\title{
Evaluation and Choosing of Recycling Technologies by Using FAHP
}

\author{
Pavlović Aleksandar $^{1^{*}}$, Tadić Danijela ${ }^{2}$, Arsovski Slavko², \\ Jevtić Dragan ${ }^{3}$, Pavlović Milan ${ }^{4}$ \\ ${ }^{1}$ Faculty of Economics and Engineering Management in Novi Sad \\ University Business Academy Novi Sad \\ Cvećarska 2, 21000 Novi Sad, Serbia, a.pavlovic@pfb-design.rs \\ ${ }^{2}$ Technical Faculty "Mihajlo Pupin" in Zrenjanin, University of Novi Sad, \\ Djure Djakovica bb 23000 Zrenjanin, Serbia, pmilan@sbb.rs \\ ${ }^{3}$ Faculty of Engineering, University of Kragujevac \\ 6 Sestre Janjic Str. 34000 Kragujevac, Serbia, galovic@kg.ac.rs, cqm@kg.ac.rs \\ ${ }^{4}$ Ministry of Spatial Planning, Civil Engineering and Ecology \\ Government of Republic of Srpska \\ Trg Republike Srpske 1, 78000 Banja Luka, Bosnia and Herzegovina, \\ d.jevtic@mgr.vladars.net
}

\begin{abstract}
The evaluation and ranking of recycling technologies for each treated waste with respects to many different criteria has important results for the management team of any recycling center. Improvement of business strategy is based on the obtained rank of recycling technologies. It represents a key success factor for a recycling center in dealing with crisis. Uncertainties in: relative importance of evaluation criteria and priority of recycling technologies under each criterion are described by triangular fuzzy numbers. Relative importance of evaluation criteria is stated by fuzzy pair-wise comparison matrices. Determining of elements values of these matrices can be considered as a fuzzy group decision making problem. Aggregation of individual opinions into group consensus is performed by using fuzzy averaging method and Fuzzy Ordered Weighted Aggregation (FOWA,) Operator Fuzzy Analytic Hierarchy Process (FAHP) is used for determination of rank of recycling technologies with respects to evaluation criteria and its weights. Proposed model is tested by example with real life data.
\end{abstract}

Keywords: waste; recycling technologies; fuzzy set; FAHP 


\section{Introduction}

Theory and management of good practice has shown a strong interest in the domain of waste management, regulated by laws and standard ISO 14000 in the large number of developed and developing countries. During the last few decades, it has been frequently employed in order to establish mechanisms for environmental protection, reducing usage of natural resources, profit increase and better competitive positioning of any enterprise. Consequently, it is possible to realize economic sustainability of every country, meeting ecology standards, by using recyclable materials and applying these different recycling technologies.

Many and varied types of uncertainty exist in a treated problem. The term uncertainty implies that in a certain situation, a person does not have a tendency, indication or they lack ability to analyze information which quantitatively and qualitatively is appropriate to describe, prescribe or predict deterministically and numerically a system, its behavior or other characteristic [23]. It is assumed that these uncertainties are far better judged by using linguistic expressions than by representing them in terms of precise numbers. It is very useful in situations, which are too complex or not well defined to be reasonably described in conventional quantitative expressions [23].

The main contribution of this paper is the introduction of a fuzzy group decision making approach and fuzzy AHP for ranking of recycling technologies for each selected type of waist. In the literature, there are many developed approaches for handling FAHP. Chang introduced a new approach with use of triangular fuzzy numbers for pair-wise comparison scale of FAHP, and use of the extent analysis method for synthetic extent value of the pair-wise comparison [5]. Use of a developed approach does not involve cumbersome mathematical operations, and it has the ability to capture the vagueness of human thinking style. With respects to opinion, the authors of this paper suggested that fuzzy AHP is appropriate for evaluation and selection of recycling technologies with respect to numerous evaluation criteria and its relative importance in an uncertain environment.

The paper is organized in the following way. The literature review is presented in Section 2. The model framework, modelling of uncertainties and base of fuzzy Analytic Hierarchical Process which is introduced in [5] is given in Section 3. In Section 4, a proposed model is illustrated by an example with real-life data. Conclusions are presented in Section 5.

\section{Literature Review}

In the literature, many papers used to describe recycling technologies of different waste types can be found in [10]; [20]; [7]; [3]. Evaluation criteria of recycling technologies of each waste type are determined by experts and stakeholders of 
each RC. It is assumed that choice of recycling technology for each type of waste is based on knowledge, experience of waste management and stakeholders of RCs.

Evaluation and selection of recycling technologies presents one of the most important management tasks of a recycling center (RCMT). By respecting selected recycling technology, necessary finances for supply of recycling equipment, could be determined by review of personal capacity, quantity of recycling material, etc. Strategy for the increase of quality of management of RCs (one of the requirements of ISO 9000:2008), and strategy of sustainable regional development may be based on the obtained results. This approach is used for explanation importance of the problem.

Solutions of the decision making problems which belong to different research areas are obtained by using proposed FAHP [5]. For instance, Kahraman et al. considered selecting of the location facility [12]. Erensal et al. have determined key capabilities in technology management [9]. Environmental risk management as part of risk analysis is treated in [21]. Chan and Kumar used FAHP in selection and ranking the best global supplier for a manufacturing firm to supply one of its most critical parts used in assembling process [6]. The priorities of organizational capital measurement indicators are determined in [4]. Assessment of water management plans in the one region of Brazil is considered in [18].

By comparing papers that propose a modified FAHP, certain differences can be noted, which are further described. This analysis, at the same time, shows advantages of the proposed model.

Selection evaluation criteria can be given according to literature data (by analogy Kahraman et al., [12]; Erensal et al. [9]; Seçme et al. [17]; Srđević and Medeiros, [18]) or results of good practice (by Tesfamariam and Sadiq []21; Chan and Kumar [6]; Bozbura and Beskese [4]). In this paper, the assumption is introduced that evaluation criteria may be selected according to assessment of stakeholders.

Many authors suggest that rating of the relative importance of criteria and priorities of attribute should be stated as fuzzy group decision making problem. Aggregation of individual opinions into a group consensus can be performed by applying different methods, for instance by using the method of fuzzy average value (Kaya and Kahraman, [13]; Tadić et al. [19]) and the fuzzy ordered weight method (FOWA) (Merigó and Gil-Lafuente [16]) in [1]. In this paper, aggregation of opinions of RCMTs is performed by fuzzy averaging method. The aggregated assessment of stakeholder is given by FOWA. With respect to nature of considered problem, these operators are used in this paper.

The modelling of the relative importance of criteria and priority of alternative is based on the fuzzy set theory. These decision variables are presented by triangular fuzzy numbers (TFNs) in all analyzed papers. Respecting this fact, in this paper is the introduced assumption that uncertainty should be modelled by TFNs. In the considered papers, criteria weights are determined by using FAHP which is 
proposed in [5]. In this paper, FAHP (by analogy [5]) is applied for determining criteria weights.

The main difference and significant contribution of the proposed FAHP that has been analyzed in this section, is calculation of values of elements of fuzzy pairwise comparison matrices. In the authors' opinion, introduced modifications of FAHP provide significantly more reliable information to decision makers than the proposed FAHP which can be seen in the literature. Therefore, RCMTs may determine the best recycling technology for each waste type.

\section{Methodology}

The evaluation and choosing of recycling technologies for each identified waste type is based as multi-criteria optimization task under uncertainties. The assessments of decision makers are described by linguistic expressions. It is assumed that it is a closer to human way of thinking that assessments are made by decision makers are represented by using linguistic expressions than precise numbers. In this paper, existing uncertainties are modelled by using fuzzy set theory [15]; [23]. In the literature, the TFNs are widely used for modelling different uncertainties. TFNs offer a good compromise between descriptive power and computational simplicity. In this paper, with respect to the type and size of the considered problem and results of investigators, five linguistic expressions are used, at the most, assigned to the existing linguistic variables. Ranking of recycling technologies for each identified waste type with respect to pre-defined evaluation criteria and their weights is given by applied FAHP, which is proposed in [5]. In literature this method is used in many papers where different problems of fuzzy multi-tasking decision making are described [17]; [22]; [13]; [19].

\subsection{The Mathematical Formulation of Treated Problem}

In this paper, reverse logistic chain (RLC) consists of a few recycling centers which can be presented by set indices $\Omega=\{1 \ldots \mathrm{j} \ldots \mathrm{J}\}$. The total number of recycling centers (RCs) of considered RLC is denoted as $J$, and $j, j=1, \ldots, J$ is index of recycling center. In general, waste is presented by set of indices $\mid=\{1 \ldots \mathrm{i}$...I $\}$, where the index of waste type is denoted as $\mathrm{i}$ and $\mathrm{I}$ is the total number of identified

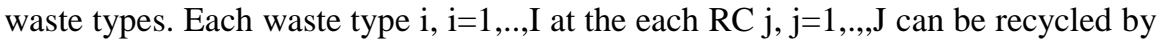
applying different recycling technologies. Recycling technology is determined for each type of waste, separately. Data base of recycling theory and their characteristics (capacity, economy characteristics, ecology characteristics, (Data bases are made by domestic and international waste management associations) employment, etc.), exists. Recycling technology of each waste type are defined by RCMT. Assessment of RCMT is based on experience, knowledge, and the initial prediction of RCMT. The recycling technologies which can be used for recycling 
of waste type $\mathrm{i}, \mathrm{i}=1, \ldots, \mathrm{I}$ are presented by set of indices $\Theta_{i}=\left\{1, \ldots ., \ldots, T_{i}\right\}$. The index of recycling technology of each waste type $i, i=1, . ., I$ is denoted as $\mathrm{t}, \mathrm{t}=1, \ldots, \mathrm{T}_{\mathrm{i}}$ and $\mathrm{T}_{\mathrm{i}}, \mathrm{i}=1, \ldots, \mathrm{I}$ is the total number of defined recycling technologies for waste type $i, i=1, . .$, I. Evaluation of recycling technologies for any identified waste types is performed with respects to many criteria. The kind and number of evaluation criteria are defined by literature sources. Formally, the evaluation criteria are presented by set indices $\chi=\{1, \ldots, k, \ldots K\}$, where $\mathrm{k}$ is index of evaluation criteria and $\mathrm{K}$ is the total number of evaluation criteria. It can be assumed that all the criteria for evaluating selected recycling technologies of each waste type are usually not of the same relative importance, and do not depend on the recycling technologies.

The fuzzy rating of the relative importance of each pair of evaluation criteria is performed by stakeholders at the recycling center level (general managers of recycling centers, managers of local administrations, and the main technology staff of recycling centers). It is supposed that stakeholders at the recycling center level make decisions by consensus. It is assumed that stakeholders of different RCs are not equal, as far as,relative importance. This assumption is introduced because of economy development, and quantity of waste and its morphology generated in different regions are not the same. The aggregation of judgements of stakeholders of considered RCs is performed by Fuzzy Ordered Aggregated Operation (FOWA) [16]. The fuzzy rating of each pair of recycling technologies under each pre-defined criterion is performed by RCMT (main manager, technology staff, manager of ecology, and financial manager). The aggregation of individual opinions of RCMTs into group consensus can be given by fuzzy averaging method.

\subsection{Modelling of Uncertainties}

Fuzzy pair-wise comparison matrix of the relative importance of evaluation criteria and treated recycling technological are stated by analogy [14]; [1].

In this paper, the fuzzy rating of stakeholders of each $\mathrm{RC}$ is described by linguistic expressions which can be represented as TFN $\tilde{\mathrm{W}}_{\mathrm{kk}}^{\mathrm{j}}=\left(\mathrm{x} ; \mathrm{l}_{\mathrm{kk}}^{\mathrm{j}}, \mathrm{m}_{\mathrm{kk^{ \prime }}}^{\mathrm{j}}, \mathrm{u}_{\mathrm{kk}}^{\mathrm{j}}\right)$. Value 1 marks the evaluation criterion $\mathrm{k}$ over evaluation criterion $\mathrm{k}^{\prime}, \mathrm{k}, \mathrm{k}^{\prime}=1, \ldots, \mathrm{K}^{\prime} ; \mathrm{k} \neq$ $\mathrm{k}^{\prime}$, has lower importance. On the other hand, the value 9 denotes that evaluation criterion $\mathrm{k}$ over evaluation criterion $\mathrm{k}^{\prime}, \mathrm{k}, \mathrm{k}^{\prime}=1, \ldots, \mathrm{K}^{\prime} ; \mathrm{k} \neq \mathrm{k}^{\prime}$ has the most importance. If strong relative importance of criterion $\mathrm{k}^{\prime}$ over criterion $\mathrm{k}$ holds, then pair-wise comparison scale can be represented by the TFB 
$\tilde{\mathrm{W}} \mathrm{kk}^{\mathrm{j}}=\left(\tilde{\mathrm{w}_{\mathrm{k}^{\prime} \mathrm{k}}^{\mathrm{j}}}\right)^{-1}=\left(\frac{1}{\mathrm{u}_{\mathrm{k}^{\prime} \mathrm{k}}^{\mathrm{j}}}, \frac{1}{\mathrm{~m}_{\mathrm{k}^{\prime} \mathrm{k}}^{\mathrm{j}}}, \frac{1}{\mathrm{l}_{\mathrm{k}^{\prime} \mathrm{k}}^{\mathrm{j}}}\right)$. If $\mathrm{k}=\mathrm{k}^{\prime}\left(\mathrm{k}, \mathrm{k}^{\prime}=1, \ldots, \mathrm{K}\right)$ then relative

importance criterion $\mathrm{k}$ over criterion $\mathrm{k}^{\prime}$ is represented by single point 1 which is a triangular fuzzy number $(1,1,1)$. Similarly, the preference of recycling technology $\mathrm{t}$ over recycling technology $\mathrm{t}^{\prime}, \mathrm{t}, \mathrm{t}^{\prime}=1, \ldots, \mathrm{T}_{\mathrm{i}} ; \mathrm{t} \neq \mathrm{t}^{\prime}$ are assessed by RCMT e, $\mathrm{e}=1, \ldots, \mathrm{E}$ by using pre-defined linguistic expressions. These linguistic expressions are modeled by triangular fuzzy numbers which are given in the following way:

Very low level importance / preferred (VL)- $(x ; 1.1 .5 .5)$

Low level importance / preferred $(L)-(x ; 1,3,9)$

Middle level importance / preferred $(M)$ - $(x ; 1,5,9)$

High level importance / preferred $(H V)-(x ; 1,7,9)$

Very high level importance / preferred $(V H)-(x ; 4.5,9,9)$

\subsection{The Proposed Algorithm}

The proposed procedure can be realized through steps.

Step 1. The fuzzy pair-wise comparison matrix of the relative importance of evaluation criteria for each $\mathrm{RC}$ are stated:

$$
\left[\tilde{\mathrm{W}}_{\mathrm{kk}}^{\mathrm{j}}\right]_{\mathrm{KxK}} \mathrm{k}, \mathrm{k}^{\prime}=1, \ldots, \mathrm{K} ; \mathrm{k} \neq \mathrm{k}^{\prime} ; \mathrm{j}=1, \ldots, \mathrm{J}
$$

Step 2. Aggregation of individual judgements of stakeholders of RCs is obtained by applying FOWA:

$$
\left[\tilde{\mathrm{W}}_{\mathrm{kk}}\right]_{\mathrm{KxK}} \mathrm{k}, \mathrm{k}^{\prime}=1, \ldots, \mathrm{K} ; \mathrm{k} \neq \mathrm{k}^{\prime} ; \mathrm{j}=1, . . \mathrm{J}
$$

where: $\tilde{W}_{k k}{ }^{\prime}=\sum_{j=1}^{J} \omega_{j} \tilde{W}_{k k^{\prime}}^{j}$ and $\omega_{\mathrm{j}}$ is the relative importance of the stakeholder of the recycling center $\mathrm{j}, \mathrm{j}=1, . . \mathrm{J}$

Step 3. The aggregated fuzzy rating of the priority of each pair of recycling technologies is given by using the fuzzy averaging method:

$$
\tilde{W}_{t, t^{\prime}}=\frac{1}{E} \tilde{W}_{t, t^{\prime}}^{e}
$$


Step 4. Calculate the criteria priority weights for each $\mathrm{RC} j, \mathrm{j}=1, \ldots, \mathrm{J}$ and recycling technologies priority preferences [5]. The weights vector represented is obtained by applying the method for fuzzy numbers comparison [2]; [8].

In a similar way, the normalized priorities vector of recycling technologies for waste type $i, i=1, . ., I$ under each identified evaluation criteria and for each waste type is:

$$
V_{t k}^{i}=\left(v_{1 i}^{i}, \ldots, v_{t k}^{i}, \ldots, v_{T_{i} k}^{i}\right) t=1, \ldots, T_{i} ; i=1, . ., I ; k=1, . ., K
$$

Step 5. The fuzzy composite priorities of the recycling technology for waste type $\mathrm{i}$, $\mathrm{i}=1, . ., \mathrm{I}$ is given:

$$
z_{t, i}=\sum_{k=1}^{K} w_{k} v_{t}^{i} k
$$

Step 6. Organize all $z_{t, i}$ in descending sequence. Recycling technology first in sequence could be considered the best for that type of waste o $\mathrm{i}, \mathrm{i}=1$,.,I.

\section{Case Study}

Developed model is tested on real life data which are obtained from the region of West Balkan. There are six recycling centers (see Fig. 1). Recycling centers $j=1$ and $\mathrm{j}=2$ are in region of Zvornik, in the region Brcko is the recycling center denoted as $j=3$, recycle centers $j=4$ and $j=5$ are in Tuzla and recycling center $j=6$ is in Trebinje.

The proposed model is tested by data from the social industry. Participation of building industry in social product of the considered region of West Balcan is about $15 \%-20 \%$. It could be said that building industries are taking a greater part in the definition of the regional development strategy. The waste is classified according to Schedule of categories of waste (Officia lGazzete Bosnia and Hercegovina No. 9/05). Choosing waste types treated in the paper is based on stakeholder's assessment and forecasted waste quantities. The six waste types: concrete ( $\mathrm{I}=1)$, brick $(\mathrm{I}=2)$, tile $(\mathrm{I}=3)$, rubber $(\mathrm{I}=4)$, plastics $(\mathrm{I}=5)$, and ash $(\mathrm{I}=6)$. Choosing of these waste types is performed with respect to two criteria: (1) estimated waste qualities which are stored and recycling in the treated RCs, and (2) demand for recycles which are obtained by applying recycling technologies. Recycling technologies for each specific type of waste are defined according to the existing data base of recycling technologies and presented in Table 1.

Table 1

Possible recycling technologies for every type of the waste 


\begin{tabular}{|l|l|}
\hline $\begin{array}{l}\text { Type } \\
\text { of waste }\end{array}$ & Possible recycling technologies \\
\hline $\mathrm{i}=1$ & $\begin{array}{l}\text { mobile recycling technologies; mobile technologies for recycling and } \\
\text { separation; mobile recycling technologies, selection and separation }\end{array}$ \\
\hline $\mathrm{i}=2$ & $\begin{array}{l}\text { cleaning for reusing; cleaning for reusing and selection; processing bricks for } \\
\text { reuse }\end{array}$ \\
\hline I=3 & $\begin{array}{l}\text { cleaning for reusing; cleaning for reusing and selectin; processing bricks for } \\
\text { reuse }\end{array}$ \\
\hline $\mathrm{i}=4$ & grinding process; grinding process and separation; grinding and pyrolysis \\
\hline $\mathrm{i}=6$ & selection; grinding process, process of pressing; \\
\hline
\end{tabular}

The number and kind of criteria used to determine mark of recycling technologies for each waste type are defined by administrations of Bosnia and Hercegovina, provinces, city administrations, owner of each considered recycling center, recycling equipment manufactories, etc. The evaluation criteria are: employment level $(\mathrm{k}=1)$, quantities of waste $(\mathrm{k}=2)$, environment impact $(\mathrm{k}=3)$, sustainable development of city and province $(\mathrm{k}=4)$, social cohesiveness of province $(\mathrm{k}=5)$, enrolment of people from different social categories $(k=6)$, level of usage of waste material $(\mathrm{k}=7)$, compliance with European Union Standards considering waste management $(k=8)$, support of domestic industry $(k=9)$, level of soil usage $(k=10)$, innovation ability of local providers $(\mathrm{k}=11)$, level of dependence based on imported material $(\mathrm{k}=12)$, and relation of price between recycled resource and price of resource on market $(\mathrm{k}=13)$.

With respect to number of populations in a considered region, kinds of industrial enterprises which exists in provinces, it is assumed that the relative importance of evaluation criteria may be defined for a group of RCs. The treated RCs are divided into three groups: the first group consists of three $R C s(j=1 ; j=2 ; j=6)$. The recycling center $(j=3)$ presents the second group of recycling centers. The third group of recycling centers consists of two recycling centers $(j=4 ; j=5)$.

The normalized weights vector of evaluation criteria is:

$\mathrm{W}=(0.103,0.085,0.085,0.107,0.066,0.077,0.106,0.095,0.075,0.035,0.033$, $0.034,0.100)$

The priorities of recycling technologies of each considered waste type under each evaluation criterion is calculated and presented in the following tables.

Table 2

The priorities of the recycling technologies under each evaluation criterion 


\begin{tabular}{|l|l|l|l|}
\hline & \multicolumn{1}{|c|}{$\begin{array}{c}\text { Vector priorities of } \\
\text { recycling technologies } \\
\text { for waste type } \mathrm{i}=1\end{array}$} & $\begin{array}{c}\text { Vector priorities of } \\
\text { recycling technologies } \\
\text { for waste type } \mathrm{i}=2 \text { and } \\
\mathrm{i}=3\end{array}$ & $\begin{array}{c}\text { Vector priorities of } \\
\text { recycling technologies } \\
\text { for waste type } \mathrm{i}=4\end{array}$ \\
\hline $\mathrm{k}=1$ & {$[0.191,0.348,0.461]^{T}$} & {$[0.333,0.333,0.333]^{T}$} & {$[0.207,0.387,0.406]^{T}$} \\
\hline $\mathrm{k}=2$ & {$[0.179,0.247,0.574]^{T}$} & {$[0.202,0.388,0.410]^{T}$} & {$[0.175,0.396,0.429]^{T}$} \\
\hline $\mathrm{k}=3$ & {$[0.258,0.334,0.408]^{T}$} & {$[0.333,0.333,0.333]^{T}$} & {$[0.447,0.297,0.256]^{T}$} \\
\hline $\mathrm{k}=4$ & {$[0.158,0.392,0.479]^{T}$} & {$[0.307,0.336,0.362]^{T}$} & {$[0.296,0.307,0.398]^{T}$} \\
\hline $\mathrm{k}=5$ & {$[0.161,0.375,0.463]^{T}$} & {$[0.291,0.338,0.371]^{T}$} & {$[0.180,0.371,0.449]^{T}$} \\
\hline $\mathrm{k}=6$ & {$[0.151,0.378,0.471]^{T}$} & {$[0.204,0.320,0.476]^{T}$} & {$[0.189,0.373,0.439]^{T}$} \\
\hline $\mathrm{k}=7$ & {$[0.122,0.352,0.526]^{T}$} & {$[0.333,0.333,0.333]^{T}$} & {$[0.301,0.329,0.370]^{T}$} \\
\hline $\mathrm{k}=8$ & {$[0.233,0.323,0.444]^{T}$} & {$[0.282,0.332,0.385]^{T}$} & {$[0.279,0.350,0.371]^{T}$} \\
\hline $\mathrm{k}=9$ & {$[0.215,0.278,0.507]^{T}$} & {$[0.215,0.271,0.513]^{T}$} & {$[0.275,0.354,0.371]^{T}$} \\
\hline $\mathrm{k}=10$ & {$[0.210,0.280,0,510]^{T}$} & {$[0.333,0.333,0.333]^{T}$} & {$[0.419,0.373,0.208]^{T}$} \\
\hline $\mathrm{k}=11$ & {$[0.291,0.332,0.377]^{T}$} & {$[0.241,0.305,0.454]^{T}$} & {$[0.333,0.333,0.333]^{T}$} \\
\hline $\mathrm{k}=12$ & {$[0.333,0.333,0.333]^{T}$} & {$[0.333,0.333,0.333]^{T}$} & {$[0.333,0.333,0.333]^{T}$} \\
\hline $\mathrm{k}=13$ & {$[0.258,0.326,0.416]^{T}$} & {$[0.557,0.370,0.073]^{T}$} & {$[0.333,0.333,0.333]^{T}$} \\
\hline & & & \\
\hline
\end{tabular}

By using the proposed algorithm (Step 5 and Step 6), the fuzzy composite priorities of the recycling technology and their rank is presented.

Applying $\left(\mathrm{t}_{3}{ }_{1}\right)$ we get have a concrete of a different granulation which has a higher market value than a recycled one, obtained by using an additional two other methods. Placed first, in the ranking is recycling technology $\left(\begin{array}{ll}t_{3} & 1\end{array}\right)$. Choosing recycling technology corresponds certain rank. The main constrain of applying this recycling technology regards to $\mathrm{RC}$ financial resources.

Table 3

The priorities of the recycling technologies under each evaluation criterion (continue)

\begin{tabular}{|c|l|c|}
\hline & \multicolumn{1}{|c|}{$\begin{array}{c}\text { Vector priorities of } \\
\text { recycling technologies for } \\
\text { waste type } \mathrm{i}=5\end{array}$} & $\begin{array}{c}\text { Vector priorities of recycling } \\
\text { technologies for waste type } \\
\mathrm{i}=6\end{array}$ \\
\hline $\mathrm{k}=1$ & {$[0.247,0.345,0.408]^{T}$} & {$[0.170,0.200,0.319,0.311]^{T}$} \\
\hline
\end{tabular}




\begin{tabular}{|c|l|l|}
\hline $\mathrm{k}=2$ & {$[0.187,0.370,0.443]^{T}$} & {$[0.250,0.250,0.250,0.250]^{T}$} \\
\hline $\mathrm{k}=3$ & {$[0.378,0.348,0.274]^{T}$} & {$[0.118,0.221,0.323,0.318]^{T}$} \\
\hline $\mathrm{k}=4$ & {$[0.247,0.338,0.415]^{T}$} & {$[0.179,0.372,0.224,0.224]^{T}$} \\
\hline $\mathrm{k}=5$ & {$[0.215,0.363,0.421]^{T}$} & {$[0.161,0.386,0.227,0.227]^{T}$} \\
\hline $\mathrm{k}=6$ & {$[0.150,0.346,0.501]^{T}$} & {$[0.351,0.147,0.207,0.237]^{T}$} \\
\hline $\mathrm{k}=7$ & {$[0.206,0.343,0.451]^{T}$} & {$[0.228,0.193,0.282,0.297]^{T}$} \\
\hline $\mathrm{k}=8$ & {$[0.282,0.316,0.402]^{T}$} & {$[0.205,0.192,0.189,0.415]^{T}$} \\
\hline $\mathrm{k}=9$ & {$[0.205,0.348,0.447]^{T}$} & {$[0.164,0.184,0.314,0.338]^{T}$} \\
\hline $\mathrm{k}=10$ & {$[0.242,0.260,0,5123]^{T}$} & {$[0.084,0.192,0.317,0.340]^{T}$} \\
\hline $\mathrm{k}=11$ & {$[0.177,0.357,0.465]^{T}$} & {$[0.161,0.081,0.321,0.336]^{T}$} \\
\hline $\mathrm{k}=12$ & {$[0.306,0.331,0.363]^{T}$} & {$[0.186,0.196,0.229,0.389]^{T}$} \\
\hline $\mathrm{k}=13$ & {$[0.225,0.311,0.464]^{T}$} & {$[0.219,0.202,0.287,0.929]^{T}$} \\
\hline
\end{tabular}

Table 4

Rank of technology used for concrete recycling ( $\mathrm{i}=1)$ :

\begin{tabular}{|l|c|c|}
\hline \multicolumn{1}{|c|}{ Type of technology } & $\begin{array}{c}\text { Total priority } \\
\text { coefficient }\end{array}$ & Rank \\
\hline Mobile recycling technology $\left(\mathrm{t}_{11}\right)$ & 0.2004 & 3 \\
\hline Mobile recycling technology and selection $\left(\mathrm{t}_{21}\right)$ & 0.3345 & 2 \\
\hline Mobile recycling technology, selection and separation $\left(\mathrm{t}_{31}\right)$ & 0.4685 & 1 \\
\hline
\end{tabular}

Table 5

Rank of technologies used for brick recycling (i=2) and tile recycling (i=3)

\begin{tabular}{|l|c|c|}
\hline \multicolumn{1}{|c|}{ Type of technology } & Total priority coefficient & Rank \\
\hline Cleaning for brick/tile reuse $\left(\mathrm{t}_{1_{2}}\right) /\left(\mathrm{t}_{1_{3}}\right)$ & 0.3124 & 3 \\
\hline Cleaning for reuse and brick/tile $\left(\mathrm{t}_{22}\right) /\left(\mathrm{t}_{23}\right)$ & 0.3357 & 2 \\
\hline Brick/tile processing for reuse $\left(\mathrm{t}_{32}\right) /\left(\mathrm{t}_{33}\right)$ & 0.3532 & 1 \\
\hline
\end{tabular}


With respect to calculated values of priority coefficient it can be concluded that each of considered recycling technologies for brick as well for tile could be in first place. It is expected because the advantage of each technology is overruled by its disadvantage. For example, applying technology $\left(t_{12}\right) /\left(t_{13}\right)$ technological level of process is lower (therefore, using this type of technology is much cheaper) but amount of labor is higher (usually unskilled). Choice of recycling technology for these two types of waste should be based on results of realized cost-benefit analysis. If wasted brick/tile is broken, then $\left(t_{1} 2_{2}\right) /\left(t_{1}{ }_{3}\right)$, or $\left(t_{2_{2}}\right) /\left(\begin{array}{lll}t_{2} & 3\end{array}\right)$ will overpower $\left(t_{3_{2}}\right) /\left(t_{3_{3}}\right)$. Otherwise, the best recycling technology is $\left(t_{3_{2}}\right) /\left(t_{3_{3}}\right)$ which is placed first in the ranking.

Table 6

Rank of technologies used for recycling of rubber ( $i=4)$ :

\begin{tabular}{|l|c|c|}
\hline \multicolumn{1}{|c|}{ Type of technology } & Total priority coefficient & Rank \\
\hline Grinding process $\left(\mathrm{t}_{14}\right)$ & 0.2815 & 3 \\
\hline Grinding processes and separation $\left(\mathrm{t}_{24}\right)$ & 0.3183 & 2 \\
\hline Grinding process, separation and pyrolysis $\left(\mathrm{t}_{34}\right)$ & 0.3712 & 1 \\
\hline
\end{tabular}

The technology $\left(\mathrm{t}_{34}\right)$ is placed first in the ranking. With respect to the given results it can be concluded that this recycling technology has the most priority compared to the other two technologies. Basic hydrocarbons obtained by using the process of pyrolysis, represents raw materials found in production of rubber and plastic products. Recycled material which we obtain by using $\left(\mathrm{t}_{34}\right)$ have a higher value in the market of reused raw materials than ones obtained by already analyzed technologies. It can be concluded that business efficiency RC could be significantly increased by applying $\left(t_{34}\right)$. The main task of RCMT can be defined as taking over management initiatives (e.g., a continuous supply to RCs of sufficient quantities of rubber which leads to application of $\left(t_{34}\right)$ will be economically justified. The main disadvantage of the technology $\left(t_{34}\right)$ compared to $\left(\mathrm{t}_{14}\right)$ and $\left(\mathrm{t}_{24}\right)$ are a higher cost of recycling. The cost of pyrolysis devices represents the majority of recycling costs by applying the technology $\left(\mathrm{t}_{34}\right)$.

Table 7

Rank of technologies used for recycling of plastic ( $i=5)$ :

\begin{tabular}{|l|c|c|}
\hline \multicolumn{1}{|c|}{ Type of technology } & Total priority coefficient & Rank \\
\hline selection $\left(\mathrm{t}_{15}\right)$ & 0.2169 & 3 \\
\hline grinding process $\left(\mathrm{t}_{25}\right)$ & 0.3182 & 2 \\
\hline pressing processes $\left(\mathrm{t}_{35}\right)$ & 0.4253 & 1 \\
\hline
\end{tabular}

With respect to the rank of recycling technologies for ( $i=5)$, it can be concluded that the dominant technology is $\left(t_{35}\right)$. Applying $\left(t_{35}\right)$ we get recycle material, which represents the final product which can be used in different types of industry. 
Market cost of recyclate acquired by using technology $\left(\mathrm{t}_{35}\right)$ is much higher than recycle materials obtained by applying technologies $\left(t_{15}\right)$ and $\left(t_{25}\right)$. Recycle material could be differently granulated which impacts its market value. Recycle material obtained by using technology $\left(\mathrm{t}_{25}\right)$ cannot be used like a final product; it is used like a raw material in production of different products in building and other branches of industry.

Table 8

Rank of technologies used in recycling of ash (i=6):

\begin{tabular}{|c|c|c|}
\hline Type of technology & Total priority coefficient & Rank \\
\hline ash separation $\left(\mathrm{t}_{16}\right)$ & 0.2015 & 4 \\
\hline recycling of flying ash $\left(\mathrm{t}_{26}\right)$ & 0.2293 & 3 \\
\hline recycling of bottom ash $\left(\mathrm{t}_{36}\right)$ & 0.2660 & 2 \\
\hline recycling and pressing $\left(\mathrm{t}_{46}\right)$ & 0.2981 & 1 \\
\hline
\end{tabular}

Importance of recycling this type of waste can be illustrated by forecasting quantities (about $360000 \mathrm{t}$ per year) and numerous and varied sources for this type of waste. Fist in the ranking is technology $\left(\mathrm{t}_{46}\right)$. This technology should not have been realized if another technology is not considered. Technology $\left(t_{46}\right)$ should be used where the final product could be transported to factories where ash is used like a production raw material. Usually, recycled ashes are used in production of cement because ash is one of the basic raw materials found in cement production.

\section{Conclusion}

Based on the results of good practice in developed countries, it is known that well organized, existing RCs have a high influence on realization of state development strategy. One of the management problems of RCMT is selection technologies which can be applied at each RC. The criteria toevaluate recycling technologies are defined by the stakeholders of RCs. It is assumed that stakeholders of treated RCs have different relative importance. The assessment and selection of recycling technologies may be introduced through identification of waste type. Assessment of defined recycling technologies priorities is performed by RCMT at the RC level. Solution of the considered problem is obtained in an exact way because the solution is less burdened by the subjective judgments of the decision makers.

The priority of selected recycling technologies with respect to all evaluation criteria and their weights is obtained by using fuzzy AHP. The elements of fuzzy pair-wise comparison matrix of the relative importance of evaluation criteria are calculated by using FOWA operator. The element of fuzzy pair-wise comparison matrix of the priority of the selected recycling technologies under each type of waste is given by using fuzzy averaging method. 
With respects to economic aspect, the worst technology is the one who gives the recycle materials numerous restrictions, insufficient funds, unskilled staff, unsuitable capacity of RC etc. Respecting constrains, choosing recycling technologies is very important for RCMTs because of that existing strategy and development of RC is based on obtained results. On other hand, improvement strategy (requirements of ISO 9001:2008, and ISO 144000) of the recycling processes should be based on obtained results.

The proposed procedure is illustrated by real-life data from RCs in the West Balcan region. Some of the possible strategies that may be employed for improving values of named RFs are: creation of partner relationships with current suppliers, increasing warehouse potential related to resources if market conditions are impacted by an unstable politic and economic situation, and development of safety-critical systems.

Besides the advantages, the proposed model has certain constraints, which are: the number of type of waste, available capacity of RC, change of number of recycling technologies for one or all considered types of waste, change of political and economic environment, etc. For a set period of time (in this case period of one year is realistic) it could be considered that selected technology has a higher priority for treated RCs.

The focus of future research should be set on a case study with a large sample of type of wastes in each RC. All of these modifications can be easily and quickly incorporated into the proposed model and do not increase the complexity of the mathematical computation. In addition, the software solution could be expanded with additional functionalities for better management of RCs.

\section{Acknowledgement}

This work was supported by the Ministry of Science and Technological Development Grant No 035033 "Sustainable development technology and equipment for the recycling of motor vehicles".

\section{References}

[1] Aleksić, A., Stefanović, M., S. Arsovski, and D. Tadić (2013) An Assessment of Organizational Resilience Potential in SMEs of the Process Industry, a Fuzzy Approach, Journal of Loss Prevention in the Process Industries, 26, 1238-1245

[2] Bass, S.M., Kwakernak, H. (1979) Rating and Ranking of Multiple-Aspect Alternatives Using Fuzzy Sets, Automatica, Vol. 3, 47-58

[3] Bolden, J., Abu-Lebdeh, T., Fini, E. (2013). Utilization of recycled and waste materials in various construction applications, American Journal of Environmental Science, Vol. 9, No. 1, 14-24.

[4] Bozbura, S. B., Beskese, A. (2007) Prioritization of Organizational Capital Measurement Indicators Using Fuzzy AHP, International Journal of Approximate Reasoning, 44, 124-147 
[5] Chang, D., Y., (1996) Applications of the Extent Analysis Method on Fuzzy AHP. European J. of Operational Research, 95 649-655

[6] Chan, S. T. F., Kumar, N. (2007) Global Supplier Development Considering Risk Factors Using Fuzzy Extended AHP-based Approach, Int. J. of Production Research, 46, 417-431

[7] de Brito, J., Robles, R. (2010) Recycled Aggregate Concrete (RAC) Methodology for Estimating its Long-Term Properties, Indian Journal of Engineering \& Materials Science, 17, 449-492

[8] Dubois, D., Prade, H. (1979) Decision-Making under Fuzziness. In Advances in Fuzzy Set Theory and Applications (ed. R. R. Yager), Ed.North-Holland, 279-302

[9] Erensal, Y. C., Oncant, T., Dermican, M. L. (2006) Determining Key Capabilities in Technology Management Using FAHP: A Case Study of Turkey. Information Science, 176, 2755-2770

[10] Hanneqaurt, C.: Good Practice Guide on Waste Plastics Recycling (2004) A Guide by and for Local and Regional Authorities. Association of Cities Regions for Recycling (ACRR), Belgium

[11] Hwang, C. and Masud, A. (1979) Multi Objective Decision MakingMethods and Applications: a State-of-the Art Survey. Springer, Berlin

[12] Kahraman C (2008) Introduction: Fuzzy Theory and Technology. Multiple Valued Logic and Soft Computing, 15(2-3) 103-115

[13] Kaya, T., Kahraman, C. (2011) Multicriteria Decision Making in Energy Planning Using a Modified Fuzzy TOPSIS methodology, Expert Systems with Applications, 38, 6577-6585

[14] Kelemenis, A, Askounis, D., (2010) A New TOPSIS-based Multi-criteria Approach to Personal Selection. Expert System with Applications, 7 (37), 4999-5008

[15] Klir, G. J., Folger, T., Fuzzy Sets, Uncertainty, and Information. Prentice Hall, Upper Saddle River, NJ., USA, 1988

[16] Merigó, J. M., Gil-Lafuente, M. A., (2011) Fuzzy Induced Generalized Aggregation Operators and its Application in Multi-Person Decision Making. Expert System with Applications, 38 (8), 9761-9772

[17] Seçme, Y. N., Bayrakdaroğu, Kahraman, C. (2009) Fuzzy Performance Evaluation in Turkish Banking Sector using Analytic Hierarchy 11709. Process and TOPSIS, Expert Systems with Applications, 36, 11699-11709

[18] Srđević, B., Medeiros, Y. D. P. (2008) Fuzzy AHP Assessment of Wather Management Plants, Wather Resources Management, Vol. 22, 877-894 
[19] Tadić, D., Gumus, T. A., Arsovski, S., Aleksić, A., Stefanović, M. (2013) An Evaluation of Quality Goals by Using Fuzzy AHP and Fuzzy TOPSIS Methodology. Journal of Intelligent \& Fuzzy Systems, 25, 547-556

[20] Tam, V. W. Y., Tam, T. C. M. (2006) A Review on the Viable Technology

for Construction Waste Recycling, Resources. Conservation and Recycling, 47 209-221

[21] Tesfamariam, T. S., Sadiq, S. R. (2006) Risk-based Environmental Decision-Making Using Fuzzy Analytic Hierarchy Process (FAHP) Stoc. Environmetal Research Risk Assessment, 21, 35-50

[22] Torfi, F., Farahani, Z., R., Rezapour, S. (2010) Fuzzy AHP to Determine the Relative Weights of Evaluation Criteria and Fuzzy TOPSIS to Rank the Alternatives, Applied Soft Computing, 10, 520-528

[23] Zimmermann, H. J. (2001) Fuzzy set Theory and its Applications. Kluwer Nijhoff Publising: Boston 